Journal of

Accident and

Emergency

Medicine 1995

12, 266-269

\title{
Senior house officers' work activities in an accident and emergency department
}

\author{
K. Y. THAM, P. W. RICHMOND \& R.J. EVANS
}

Accident and Emergency Department, Cardiff Royal Infirmary, Newport Road, Cardiff CF2 1SZ, UK

\section{SUMMARY}

A study of senior house officers' daytime work activities was conducted in the accident and emergency department of the Cardiff Royal Infirmary. Activities were timed every 15 seconds by a single observer and were subdivided into working periods, meal periods and periods when no patient was waiting to be seen. A total of $96.1 \mathrm{~h}$ was analysed. The SHOs were found to be working for $78 \%$ of their time, of which $18.5 \%$ was taken up by nondoctor tasks. The SHOs took an average of $\mathbf{1 0 . 4}$ min for each walking wounded patient, $10.6 \mathrm{~min}$ for each paediatric patient and $27.3 \mathrm{~min}$ for a trolley patient. Each patient required an average of $14.2 \mathrm{~min}$ for assessment and treatment, which meant that 3.3 patients were seen each hour. However, considering that SHOs worked for $78 \%$ of their time, the actual rate of work was 4.2 patients for each working hour. The implications for staffing are discussed.

Key words: daytime work activities, senior house officers, staffing levels

\section{INTRODUCTION}

The accident \& emergency (A\&E) department of the Cardiff Royal Infirmary is a large department with over 75000 new attendances each year. The department has a separate paediatric area that treats over 20000 new attendances each year. The department is staffed by two consultants, two senior registrars, one staff grade and 12 senior house officers (SHOs). The SHOs work a 40-h week. There are four work areas within the department: a twobedded resuscitation room; a nine-bedded trolley area; a five-roomed walking wounded area; and a four-roomed paediatric area. There is an operational nurse triage system that comprises 25 nurses. The nurses also have extended roles and many are able to suture lacerations on the scalp, arms and legs (excluding hands). A nurse practitioner scheme operates within the department which comprises five nurses who treat and discharge $1.5 \%$ of the new patient workload.

The study investigated the SHOs' daytime activities, both clinical and non-clinical, and quantified these activities through the working day.

\section{METHODS AND SUBJECTS}

From the departmental computer database, the mean number of patients seen by each $\mathrm{SHO}$ within the previous four months was determined. The four SHOs whose numbers of new patients seen were nearest the mean were selected for the study. The SHOs in the study saw a total of 9358 new patients during their six-month attachment, during which they worked a 40 hour week (i.e. standard SHO equivalent); if extrapolated, this equates to 4679 new patient attendances for each $\mathrm{SHO}$ each year. This compares with the British Association for Accident and Emergency Medicines' standard SHO equivalent of one doctor for each $\mathbf{4 0 0 0}$ new patient attendances.

Initially a pilot study was conducted on three consecutive mornings from 0900 to $1300 \mathrm{~h}$, during which a SHO was observed. The observer (K.Y.T.) timed and recorded the various activities, to the nearest $15 \mathrm{~s}$, with a stopwatch. Fourteen activities were identified (Table 1).

During the main study a total of $96.1 \mathrm{~h}$ was observed and recorded. A total of $47.8 \mathrm{~h}$ was weekday duty and $48.3 \mathrm{~h}$ weekend duty. The SHOs were studied from 0900 to $1600 \mathrm{~h}$ for morning duty and from 1600 to $0100 \mathrm{~h}$ for evening duty. The study was carried out over a four-week period from December 1993 to January 1994 when the SHOs had been in post for approximately five months of their six-month rotation.

During the study, the SHOs moved freely among the various areas within the department. Each SHO was encouraged to ignore the observer as much as possible. When they needed advice about patient management, they were encouraged to look for another senior member of the department. The use of a single observer eliminated the problem 
SHOs' activities in A\&E
Table 1. Clinical activities of accident and emergency senior house officers

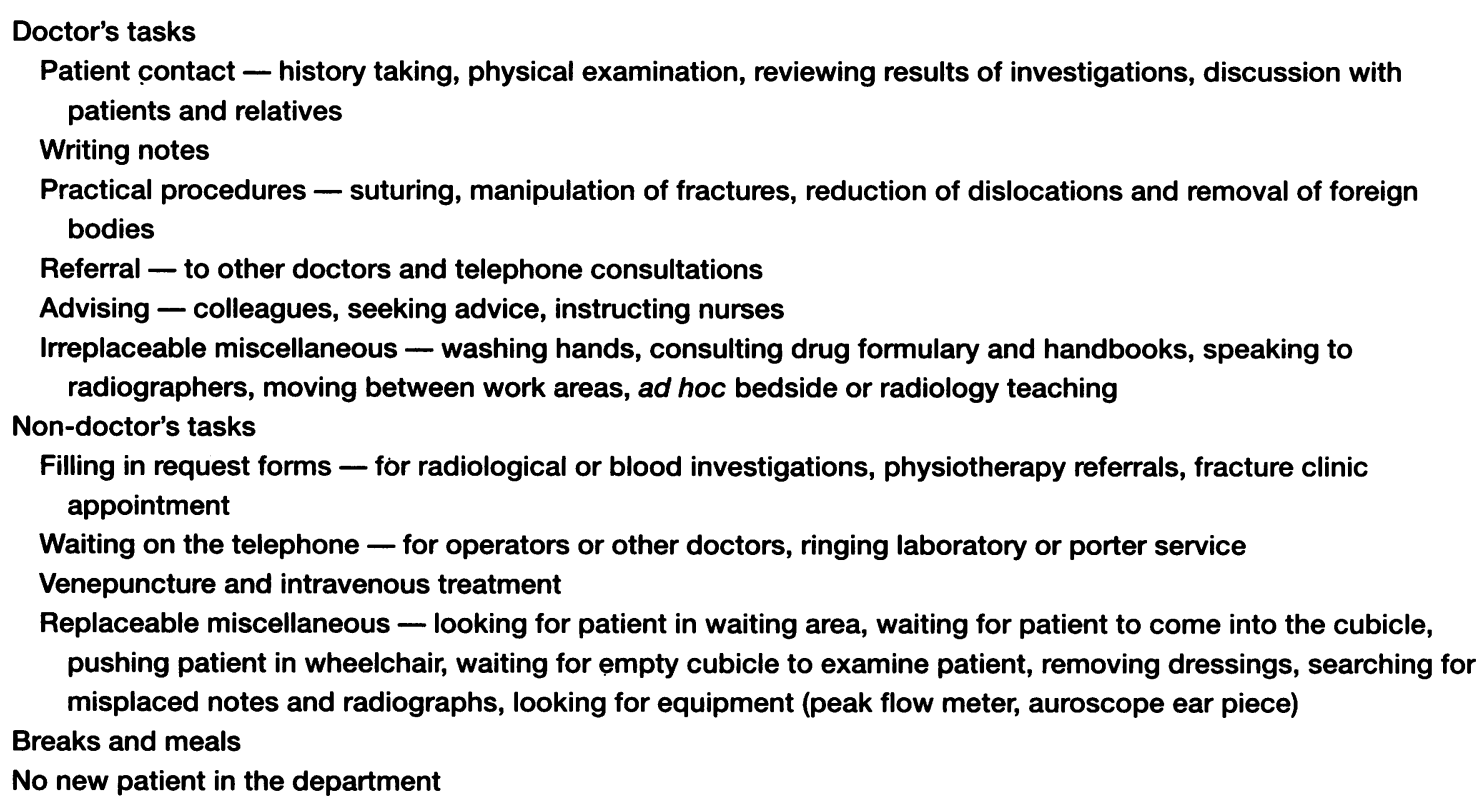

of inter-observer variation. The observer had worked as an A\&E SHO for a year and she was familiar with the unique work environment and varied clinical activities within it.

\section{RESULTS}

\section{Hours of work}

A total of $96.1 \mathrm{~h}$ was analysed. The SHOs spent $74.9 \mathrm{~h}(77.9 \%)$ working, $5.4 \mathrm{~h}(5.6 \%)$ of their time having breaks and meals and the remaining $15.8(16.4 \%)$ were spent waiting in the department as no patient was waiting to be seen. Table 2 shows the mean proportion of working and non-working times. There was little difference in the amount of time spent working when comparing weekend and weekday duties and morning and evening duties.

Of the $15.8 \mathrm{~h}$ when there was no new patient in the department, $7.6 \mathrm{~h}(48.1 \%)$ were between 0900 and $1100 \mathrm{~h}$ and 2200 and $0100 \mathrm{~h}$. The SHOs tended to take their breaks during that time when the department was quiet and hence only $5.7 \%$

of the time was actually recorded as breaks and meals.

\section{Area and rate of work}

Three hundred and sixteen patients were seen during the study and the patient mix is categorized as follows: $180(57.0 \%)$ were walking wounded patients; 68 (21.5\%) were trolley patients; 67 (21.2\%) were paediatric patients and one $(0.3 \%)$ required resuscitation. Table 3 shows the distribution of working time among the different work areas.

Each patient required an average of $14.2 \mathrm{~min}$ for assessment and treatment, which meant that $\mathbf{3 . 3}$ patients were seen each hour. However, considering that $74.9 \mathrm{~h}$ were the actual number of hours worked, the rate of work was 4.2 patients for each working hour.

\section{Range of activities}

Table 4 shows the mean proportions of working time spent on various clinical activities. Of the

Table 2. Mean number (percentage) of working and non-working times (hours)

\begin{tabular}{lcccccc}
\hline & \multicolumn{2}{c}{ Morning duty } & \multicolumn{2}{c}{ Evening duty } \\
& $\begin{array}{l}\text { Weekday } \\
(n=21.9 \mathrm{~h})\end{array}$ & $\begin{array}{l}\text { Weekend } \\
(n=21.2 \mathrm{~h})\end{array}$ & $\begin{array}{c}\text { Weekday } \\
(n=25.9 \mathrm{~h})\end{array}$ & $\begin{array}{l}\text { Weekend } \\
(n=27.1 \mathrm{~h})\end{array}$ & $\begin{array}{c}\text { Average } \\
(\%)\end{array}$ \\
\hline Working & $17.5(79.9)$ & $15.7(74.1)$ & $21.1(81.5)$ & $20.6(76.0)$ & 77.9 \\
No patient & $3.3(15.1)$ & $4.1(19.3)$ & $3.6(13.9)$ & $4.8(17.7)$ & 16.5 \\
Breaks and meals & $1.1(5.0)$ & $1.4(6.6)$ & $1.2(4.6)$ & $1.7(6.3)$ & 5.6 \\
\hline
\end{tabular}


K.Y. Tham et al.

\begin{tabular}{lcccc}
\hline & $\begin{array}{c}\text { Resuscitation } \\
\text { room } \\
(n=1)\end{array}$ & $\begin{array}{c}\text { Trolley area } \\
(n=68)\end{array}$ & $\begin{array}{c}\text { Walking } \\
\text { wounded } \\
(n=180)\end{array}$ & $\begin{array}{c}\text { Paediatric } \\
(n=67)\end{array}$ \\
\hline Total time (h) & 0.9 & 30.9 & 31.1 & 11.9 \\
Time spent & 4 & 27.3 & 10.4 & 10.7 \\
$\begin{array}{l}\text { with each } \\
\text { patient (min) }\end{array}$ & & & & \\
\hline
\end{tabular}

Table 3. Distribution of working time among work areas doctor's tasks, the amount of time spent on patient contact $(39.7 \%)$ was the largest, with the time taken to write clinical notes (18.7\%) next. There was again little difference in the proportion of time spent on these activities between weekday and weekend duties and between morning and evening duties.

\section{DISCUSSION}

The study reveals that SHOs in an A\&E department are working for a considerable proportion of their daytime shift $(77.9 \%)$ and that most of this time is spent on doctor's tasks $(81.5 \%)$. The SHOs activities examined did not include any night-time periods, i.e. 0100-0900 h. However, it was surprising that in a large A\&E department, for $16.4 \%$ of their time they had no patient to attend to. It was of interest to note that almost half of this time was at the beginning of the morning shift and at the end of the evening shift.

Previous studies in the UK have looked at the workload and work patterns of junior doctors on medical and surgical wards. A study of pre-registration medical house officers showed that the hours of duty ranged from 83 to $101 \mathrm{~h}$ each week and that between 50 and $71 \%$ of house officers' time was spent on patient-orientated duties during the day, but this fell to between 21 and $53 \%$ at night. ${ }^{1}$ Another study revealed that SHOs and preregistration house officers spent nearly half of all their on-call duty time working, but less than half of that time was spent in direct contact with patients. This study concluded that the workload while on duty was excessive and that changes in some administrative procedures and the employment of non-medical staff might reduce the time spent on non-clinical activities, thereby reducing the overall workload and allowing more time for patient contact. ${ }^{2}$ One common theme in these studies was the identification of tasks that were time consuming, but contribute little to the doctors' training. In our study, these have been described as non-doctor tasks and occupied $18.5 \%$ of their working time.

Table 4. Mean proportion of working time spent on various clinical activities

\begin{tabular}{|c|c|c|c|c|c|}
\hline \multirow[b]{2}{*}{ Activity } & \multicolumn{2}{|c|}{ Morning duty } & \multicolumn{2}{|c|}{ Evening duty } & \multirow[b]{2}{*}{ Average } \\
\hline & Weekday & Weekend & Weekday & Weekend & \\
\hline \multicolumn{6}{|l|}{ Doctors tasks } \\
\hline Patient contact & 34.7 & 47.6 & 36.7 & 41 & 39.7 \\
\hline Writing notes & 16.6 & 23.1 & 17.2 & 18.8 & 18.7 \\
\hline Practical procedures & 7.1 & 0.4 & 2.6 & 3.3 & 3.4 \\
\hline $\begin{array}{l}\text { Referrals and } \\
\text { telephone consultations }\end{array}$ & 2.4 & 3.4 & 4.6 & 7.8 & 4.7 \\
\hline $\begin{array}{l}\text { Seeking/giving advice, } \\
\text { Instructing nurses }\end{array}$ & 6.3 & 2.8 & 4 & 5.3 & 4.6 \\
\hline Irreplaceable miscellaneous & 13.4 & 9.5 & 11.5 & 7.3 & 10.4 \\
\hline Subtotal & 80.4 & 86.6 & 76.6 & 83.5 & 81.5 \\
\hline \multicolumn{6}{|l|}{ Non-doctor's tasks } \\
\hline Filling in forms & 4.8 & 3.8 & 4.1 & 3.4 & 4 \\
\hline Waiting on telephone & 2.3 & 1.1 & 4.3 & 2.3 & 2.6 \\
\hline $\begin{array}{l}\text { Venepuncture and } \\
\text { intravenous treatment }\end{array}$ & 2.9 & 0.6 & 3.4 & 3.4 & 2.7 \\
\hline Replaceable miscellaneous & 9.6 & 7.7 & 11.7 & 7.3 & 9.1 \\
\hline Subtotal & 19.5 & 13.2 & 23.6 & 16.5 & 18.5 \\
\hline
\end{tabular}


SHOs' activities in A\&E
There are ways to relieve the SHOs of such tasks. We question the need for A\&E SHOs to undertake some of these duties. This is especially so for 'routine' haematological and biochemistry blood investigations. If the A\&E SHOs limit themselves strictly to blood investigations that would influence their management (e.g. BM stix, plasma paracetamol level and arterial blood gases), the number of venepunctures and forms to be filled in would be reduced. Alternatively, the employment of nonmedical staff, e.g. a phlebotomist to relieve the doctor of such tasks, is worthy of consideration. Another possibility that could be explored is the employment of a doctor's assistant, who could relieve the SHO of their clerical, administrative duties and some of the miscellaneous activities, e.g. bringing a patient into a cubicle, removing dressings or fetching equipment. The nursing staff in A\&E departments are continually extending their role and again this will aid the doctor's workload. Finally, simple modifications within the department and better house-keeping will help to further reduce some of the replaceable miscellaneous activities.

The SHOs adopted a positive attitude towards the study and when the results were presented to them a number of constructive suggestions on improvements within the department were made. Some of these suggestions have since been implemented. These included the introduction of better sign-posting to areas within the department, such as the fracture clinic and radiography department, which now helps to eliminated the need for repeated directions from the doctors to their parents.

A prospective time study of emergency doctor workload in Connecticut, USA revealed that the doctors' service time for non-selected service patients was 24.2 min for each patient. However, the study showed that this time varied significantly from the standard walk-in (9.8 $\mathrm{min}$ for each patient), observation (55.6 min for each patient) and critical care patient (31.9 $\mathrm{min}$ for each patient). ${ }^{3}$ Our findings showed that the time for walking wounded patients, both adults (10.4 min for each patient) and children (10.6 min for each patient), was similar to that of the standard walk-in patients (9.8 min for each patient) in the Connecticut time study. The Cardiff Royal Infirmary's paediatric A\&E department treats mainly minor injuries as the seriously ill or injured children are seen in the trolley or resuscitation areas. This probably accounts for the finding that the time needed to assess and treat each child is similar to that for an adult walking wounded patient.

The trolley patients took on average $27.3 \mathrm{~min}$ for each patient, which compares with the Connecticut studies critical care patient time of $31.9 \mathrm{~min}$. Our study only included one resuscitation patient and thus is not able to make any meaningful estimation of the average time taken for assessment and treatment.

The conclusion of the Connecticut study was that the case mix of patient services affected the emergency doctors' workload and should be considered in planning departmental staffing needs. ${ }^{3}$ We would endorse this viewpoint.

Another way of estimating the required staffing level that has been suggested in the UK is by the use of activity-related groups. ${ }^{4}$ These are categories of patient as defined by severity of illness and average time spent with them.

Activity-related groups have been used at Barnet General Hospital and it was admitted that the time assigned to a group needed further validation, but that it was difficult to measure this accurately. ${ }^{4}$ The findings from our time study could provide a means of estimating staffing requirements within our department based on patients by their allocation to a specific area. However, to be confident of its validity we suggest that this should include observation of more SHOs and over their 6-month period in post.

\section{ACKNOWLEDGEMENTS}

We thank Dr J.C. Evans, Dr R.O.N. Evans, Dr E.J. Rubython and Dr R.S. Williams for their participation in the study.

\section{REFERENCES}

1. Leslie P.J., Williams J.A., McKenna C., Smith G. \& Heading R.C. (1993) Hours, volume, and type of work of preregistration house officers. British Medical Journal 300, 1038-1041.

2. Turnbull N.B., Miles N.A. \& Gallen I.W. (1993) Junior doctors' on call activities: differences in workload and work patterns among grades. British Medical Journal 301, 1191-1192.

3. Graff L.G., Wolf S., Dinwoodie R., Buono D. \& Mucci D. (1993) Emergency physician workload: a time study. Annals of Emergency Medicine 22, 1156-1163.

4. Crone P.W. \& Whitlock M.R. (1993) The role of activity-related groups in assessing workload in the accident and emergency department. Archives of Emergency Medicine 10, 212-215. 